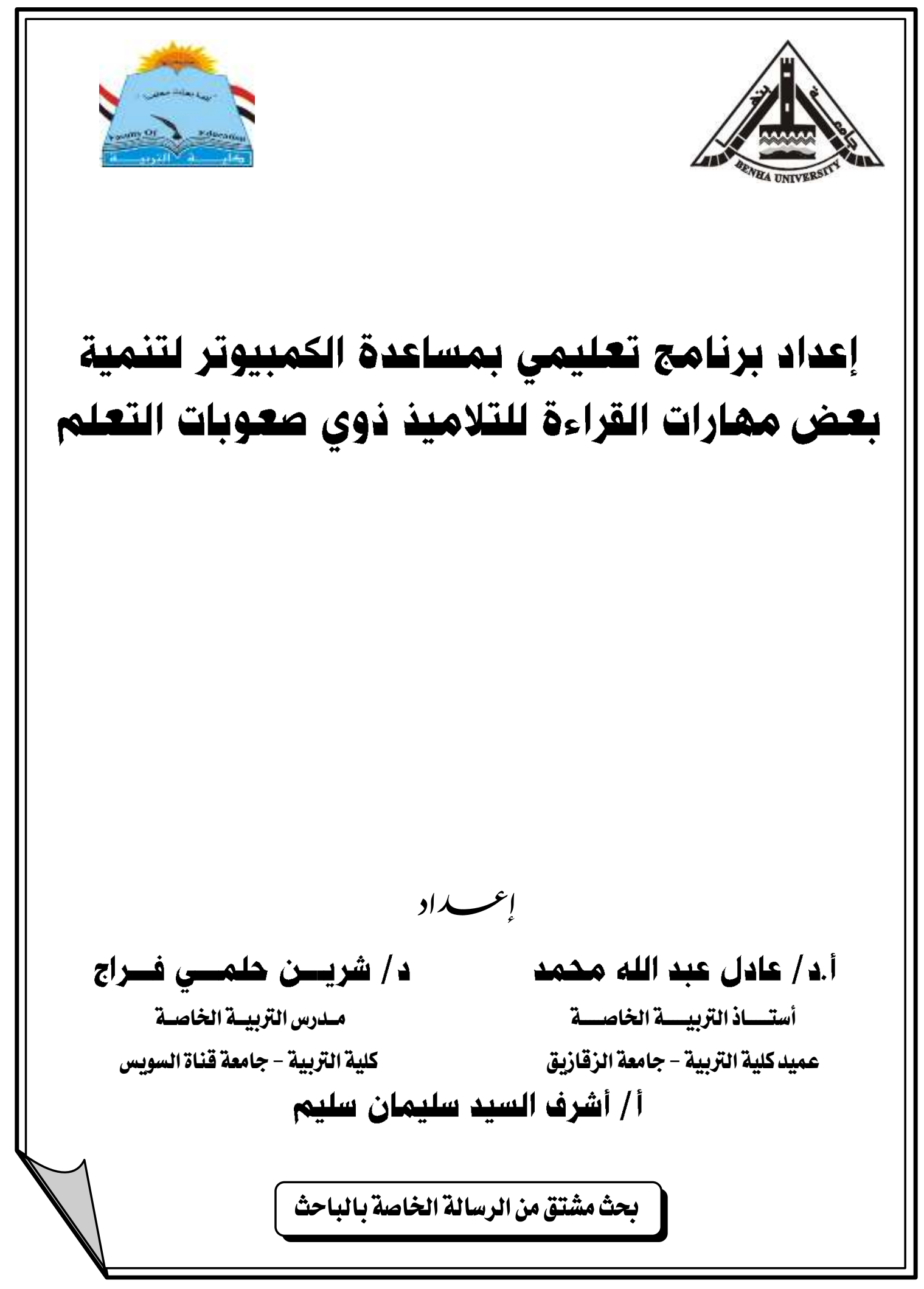




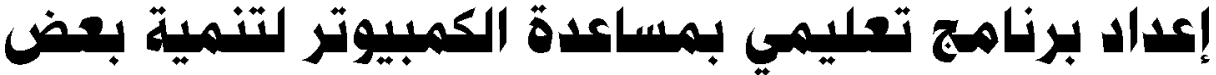

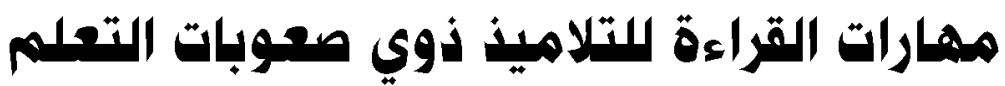

\author{
" ! ! \\ ه/ شريسن هلمــي فـراج \\ مدرس التربية الخاصة \\ كلية التربية - جامعة قناة السويس التراسة \\ أ.د / عادل عبد الله محمد \\ أستاذ التربية الخاصة - عميل كلية التربية \\ جامعة الزقازيق \\ أ أشرف السيد سليمان سليم كليمانية
}

\section{مقدمسسة البرناهــــة:}

يتميز العصر الحالي بالتغير المستمر، والتطور السريع في جميع مجالات الحياة، مما

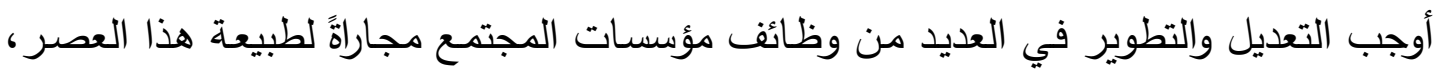

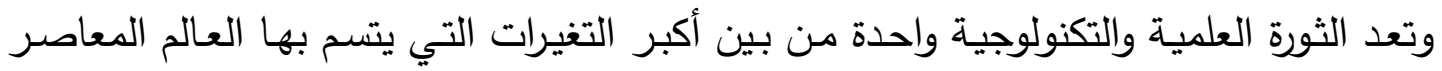

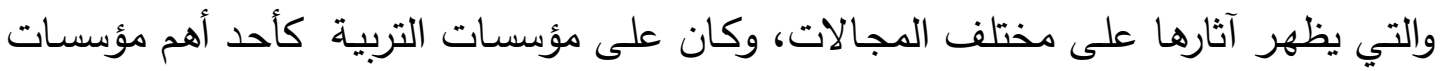
المجتمع أن تستجيب لتلك الثورة التكنولوجية بحيث تعكس في برامجها عناصر هذه التكنولوجيا

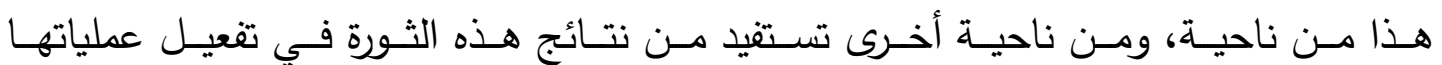
وتحقيق أهدافها.

و الكمبيـوتر كأحـــــــهـ المستحدثات التكنولوجيـة أصـبح أمـر ضـروري في العمليـة

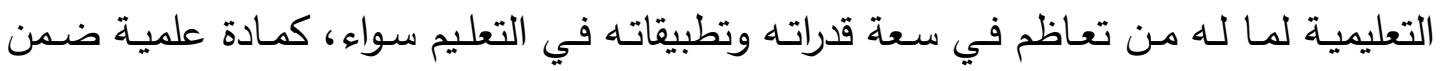
المناهج الدراسية أو كوسيط تعليمي، أو في الإدارة التعليمية. وقد بدأ الاهتمام في السنوات الأخيرة ينصب على الإدانى استخدام الكمبيوتر في مجال التربية

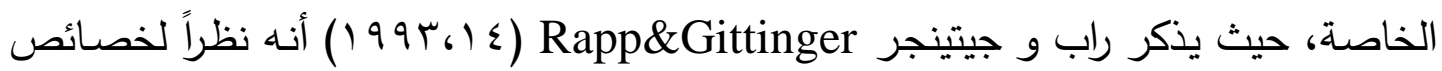

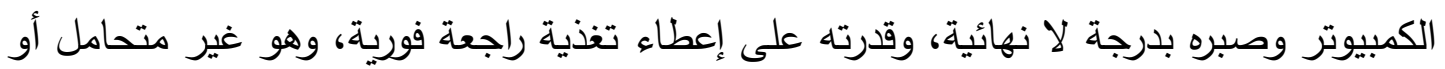

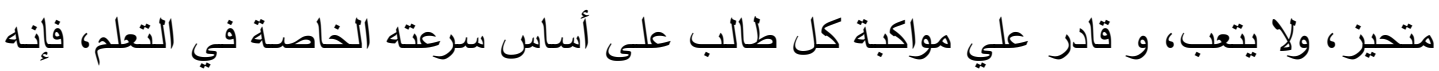
من المكن أن يساهم بفاعلية في زيادة تحصيل الطلاب من ذوي الإبل الاحتياجات الخاصة.

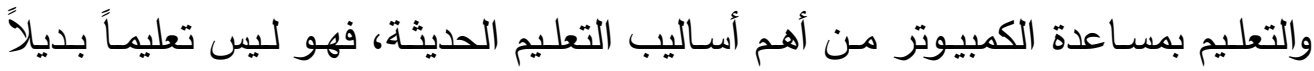

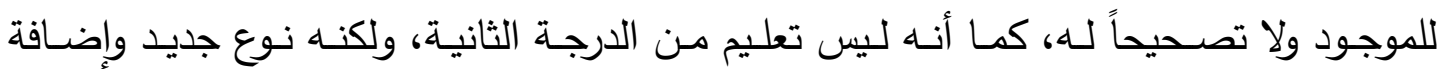


للموجود لمواجهة موقف جديد بأدوات إضـافية ليتكامل مـع الموجود ويمثل عنصر تقدم بمـا

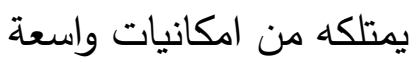

\section{هـدف البرنسامــاج:}

يهاف البرنامج إلى تتمية بعض مهارات القراءة لدى تلاميذ الصف الرابع الابتدائي ذوي

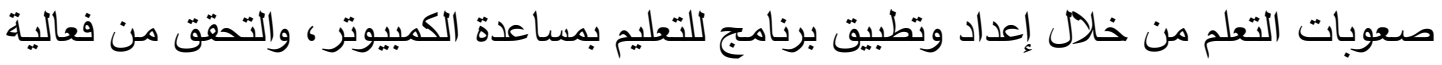

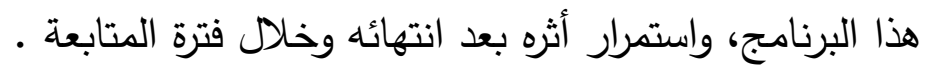

\section{أهميـة البرنامـــة}

\section{تتضح أهمية البرنامج من خلال:}

تسهم في تتمية مهارات القراءة لذوي صعوبات تعلم القراءة في الصف الرابع الابتدائي من خلال تصميم برنامج للتعليم بمساعدة الكمبيوتر ل اهتمامها بفئة من تلاميذ المدارس الابتدائية ذوي الذكاء المتوسط أو أعلى من المتوسط، ورغم ذلك يعانون من قصور تحصيلي في تعلم مهارات القراءة . تحديد مدى فعالية التعليم بمساعدة الكمبيوتر في تتمية مهارات القراءة للى الطلاب

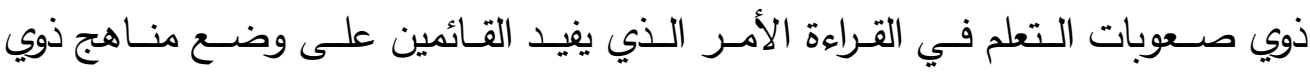
الصعوبات التعلم في اختيار الوسائل المناسبة لتدريس مادة التراءة في المرحلة الابتدائية. ه تزويد القائمين على تصميم وإنتاج برامج الكمبيوتر للجموعة من الإرشادات المعيارية

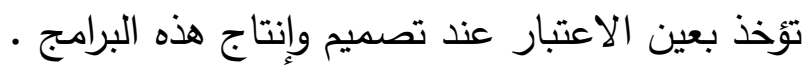

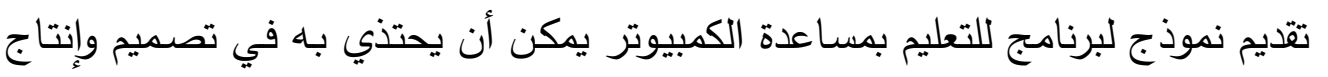

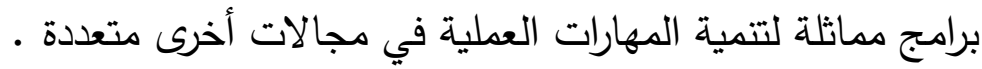

\section{مبـررات البرناهـــة:}

تتطلب الدراسة الحالية إعداد مقياس لقياس مدى تحصيل التلاميذ ذوي صعوبات التعلم في القراءة لمهارتي التعرف على الكلمة والفهم القرائي وقام الباحث بإعداد هذا المقياس للأسباب التالية:

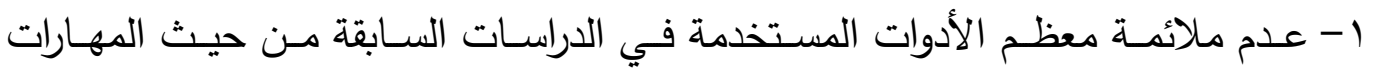

$$
\text { المطلوب قياس التحصيل فيها. }
$$

r- عدم مناسبة معظم البنود في المقاييس السابقة مع طبيعة عينة البحث وهم التلاميذ ذوي صعوبات تعلم القراءة في الصف الرابع الابتدائي. 
r- معظم المقاييس السابقة لا تستخدم الكمبيوتر في الاختبار وهذا لا يتتاسب مع الدراسة الحالية.

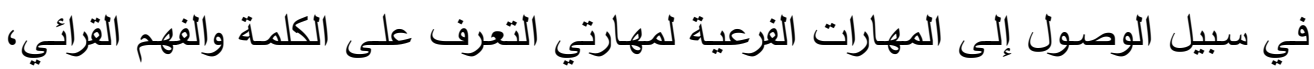
التي ينبغي تتميتها لدى تلاميذ الصف الرابع الابتدائي ، قام الباحث بيناء استبانة لتحقيق هذا لهاتيا الغرض وتطلبت إجراءات بنائها ما يلى: استبانة تحديد مهارتي التعرف على الكلمة وإلفهم القرائي:

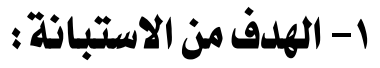

تهدف هذه الاستبانة إلى تحديد مهارتي التعرف على الكلمة والفهم القرائي، اللازمـة لتلاميذ الصف الرابع الابتدائي، من وجهة نظر الخبراء والمتخصصين في مجال تدريس القراءة.

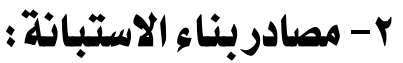

اعتمد الباحث عند بناء الاستبانة على المصادر التالية:

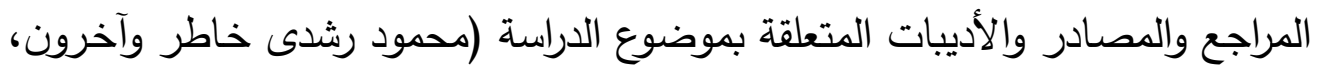

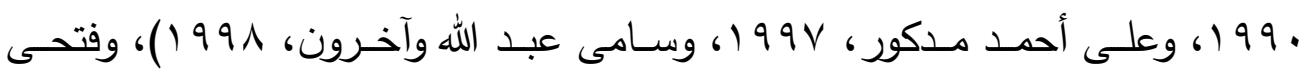

$$
\text { يونس، ع ع (19) ). }
$$

الدراسات والبحوث السابقة المتعقة بموضوع الدراسة (جمال مصطفى العيسوى (99 199،

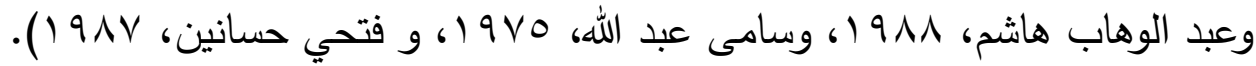
• أهداف تدريس اللغة العربية بالمرحلة الابتدائية كما حددتها الوزارة.

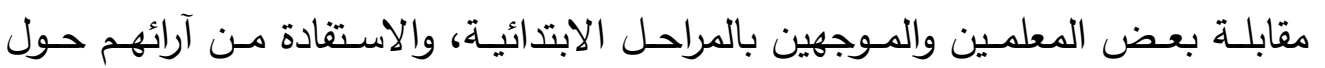

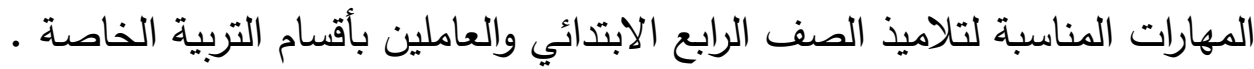

r- الاستبانة في صورتها الأولية : تم بناء الاستبانة فى صورتها الأولية، وإثتملت على محورين أساسين: المحور الأول: خاصر بتصديد مهارات التنعرف على الكلمة: وزعت المهارات فى هذا المحور فى شكل تراكمى بدءً من مستوى نطق الحرف، وقد اشتمل هذا المحور على الأبعاد التالية: • نطق الحروف نطقاً صحيحاً. 


$$
\begin{aligned}
& \text { - ربط بين صوت الحرف وشكله. } \\
& \text { • تميز بين الحروف المتثابهة رسماً والمختلفة لفظاً مثل (ج ،ح) ، (ت،ث). } \\
& \text { تفريق بين الحروف المتشابهة لفظاً والمختلفة رسماً مثل (ك ، ق) ،(س ، ز). } \\
& \text { تميز بين الحرف المدود والحرف غير المدود. } \\
& \text { يميز بين حركات التتوين. } \\
& \text { يفرق بين اللام الثدسية واللام القدرية. } \\
& \text { يميز بين التاء المفتوحة والتاء المربوطة. }
\end{aligned}
$$

المهور النانيي: خاص بـتهديد مهارات الفهم القرائي :

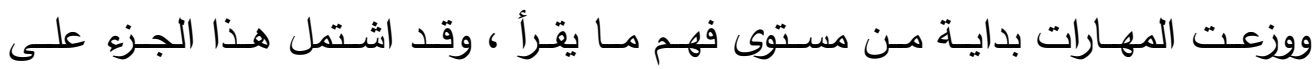

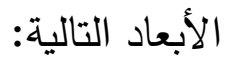

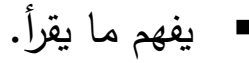

$$
\begin{aligned}
& \text { يفهم التلميحات في السياق والكلمات. } \\
& \text { ـ يفر معاني الكلمات. } \\
& \text { " يكتشف الفكرة الأساسية في النص. } \\
& \text { يرتب الأحداث الواردة في النص. } \\
& \text { يعيد تركيب المعلومات الواردة في النص. } \\
& \text { يقترح عنوان جديد للنص. }
\end{aligned}
$$

وتم استخدام مقيـاس التقدير ثلاثى الأبعاد للسؤال عن مدى مناسبة المهارة لتلاميذ الصـف الرابـع الابتـدائى ذوي صـوبات التعلم (مناسـبة - غيـر مناسـبة - يمكن تعـيلها)، واستخدام المقياس الثنائى للسؤال عن مدى ارتباط المهارات الفرعية بالمهارة الرئيسية التى تتتمى إليها (ترتبط - لا ترتبط).

\section{ع- تعليمات الاستجابة على الاستبانة:}

اهتم الباحث بخطوة إعداد التعليمات، بحيث شملت الهدف من الاستبانة، وروعى فيها

$$
\text { أن تكون واضحة ومختصرة، وتوضتح للمستجيب الإجابة عن كل العناصر • }
$$




\section{النأكد من صلاصية الاستبانة:}

للتأكد من صدق الاستبانة ثم عرضها على مجموعة من المتخصصين فى طرق تدريس اللغة العربية، والتربية الخاصة، وعلم النفس، وبعض موجهى ومعلمى اللغة العربية، وطلب منهم إبداء الرأى فى الاستبانة من حيث:

مدى مناسبة المهارة لتلاميذ الصف الرابع الابتدائى •

مدى ارتباط المهارات الفرعية بالمهارة الرئيسة.

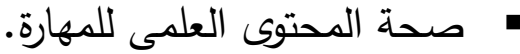

سلامة الصياغة اللغوية للمهارة.

• نقل بعض المهارات من مستوى إلى مستوى آخر •

• حذف، أو تعديل، أو إضافة مهارات أخرى.

دقة تعليمات الاستجابة على الاستبانة.

وفى ضوء ملاحظات المحكمين تم مراجعة تصميم الاستبانة، وكان لبعض المحكمين بعض الآراء والتوجيهات التى أخذت فى الاعتبار ، ومنها ما يلى: • اقترح بعض المحكمين تعديل صياغة بعض المهارات مثل: • (يستنتج صوت الحرف من شكله) إلى (ربط بين صوت الحرف وشكله. • (يركب معلومات النص ) إلى (يعيد تركيب المعلومات الواردة في النص). تصديد مهارات التعرف على الكلمة والفهم القرائي:

تم توزيع الاسبتانة على عدد من المتخصصين فى مجال تدريس اللغة العربية، وبتحليل البيانات عن طريق حساب نسب الاتفاق بين المحكمين باستخدام النسب المئوية توصل الباحث إلى قائمة بمهارات التعرف على الكلمة والفهم القرائي المناسبة لتلاميذ الصف الرابع الابتدائى

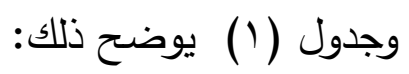




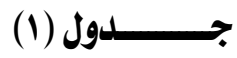

نسب اتفاق المحكمين على مهارات التعرف على الكلمة والفهم القرائي المناسبة لتلاميذ الصف الرابع الابتدائى

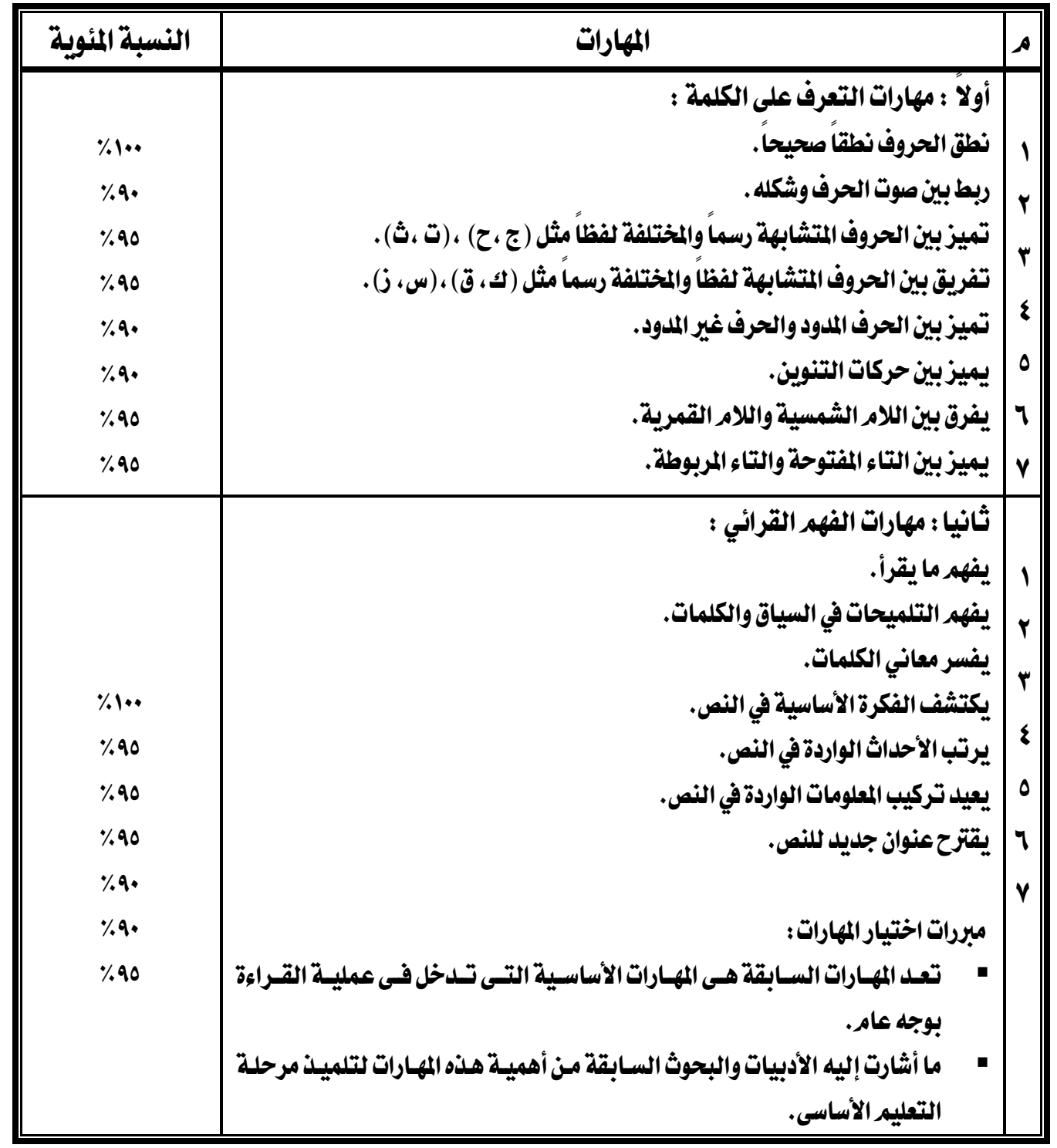

• ما ذكره بعض معلمى وموجهى المرحلة الابتدائية من ضعف التلاميذ فى هذه المهارات. • إمكانية تتميتها لدى التلاميذ من خلال الوسائل الكمبيوترية المتعددة.

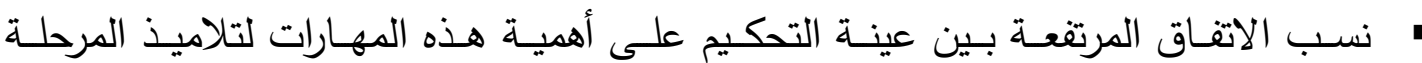
الابتدائية؛ حيث أظهرت معاملات الاتفاق بينهم على مناسبة هذه المهارات لتلاميذ الصف الرابع الابتدائى، وقد اختيرت المهارات التى تراوح اتفاق المحكمين على اهميتها لتلاميذ الصف الرابع الابتدائي (بين •9 - . . 1\%) والجدول ( 1 ) يوضح ذلك. 
ووفقاً لما سبق قام الباحث بإعداد اختبار تحصيلي لمهارتي التعرف على الكلمة والفهم القرائي للتلاميذ ذوي صعوبات تعلم القراءة في الصف الرابع الإبت لابتدائي.

فطوات بناء الافتبار :

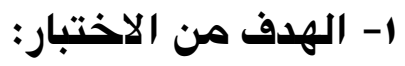

يهدف هذا الاختبار إلى قياس الجانب التحصيلي المتصل بمهارتي التعرف على الكلمة والفهم القرائي لدى تلاميذ الصف الرابع الابتدائي. r- إعداد قائمة بالأهداف المعرفيتة للاختبار:

فى ضوء نتائج استبانة تحديد المهارات اللازمة لتلاميذ الصف الرابه لإديع الابتدائى، قام

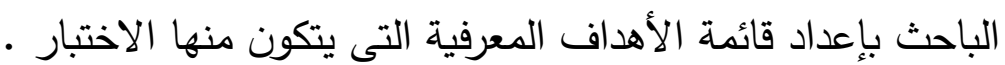
r- r- إعداد جدول المواصفات:

قام الباحث بتحليل مهارتي التعرف على الكلمة والفهم الترائي تحليلاً دقيقاً بهدف: بيان أوجه التعلم فى كل مهارة. صياغة الأهداف السلوكية المرتبطة بكل مهارة.

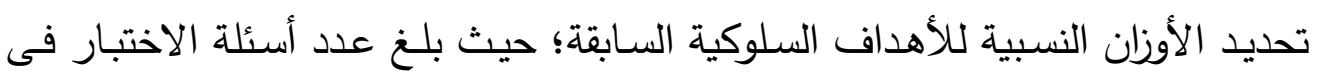

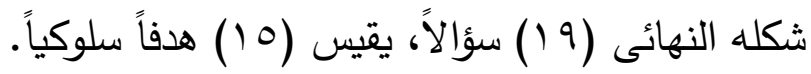

ع- صياغته مفردات الاختبار: فى ضوده جدول المواصفات، وتحديد الأوزان النسبية للأهداف السلوكية، قام الباحث

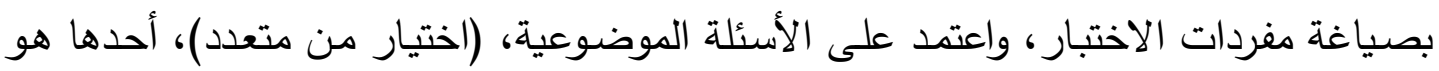

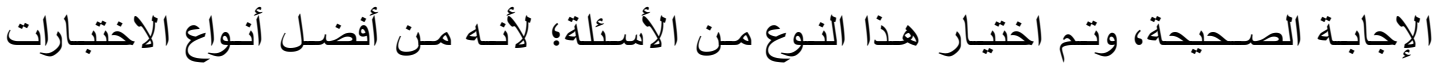

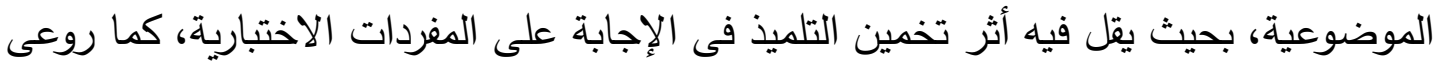

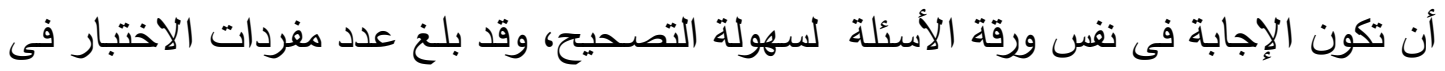
صورته الأولية (r T) مفردة شملت جميع جوانب السلوك المقاس.

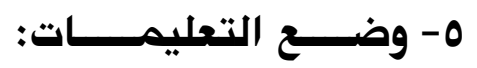

اهتم الباحث بخطوة إعداد تعليمات الاختبار ، لأن عدم دقة التعليمات قد يؤدى إلى

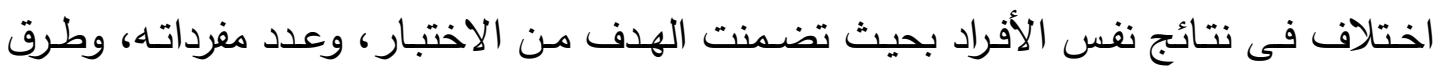

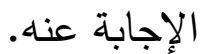


وروعى فيها أن تكون سهلة، ومباشرة، وواضحة تماماً، وتوضح للتلاميذ ضرورة الإجابة عن جميع مفردات الاختبار ، وتتضمن مثالاً مجاب عنه.

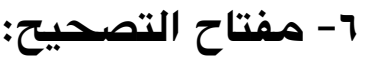

تم تصحيح الاختبار على أساس جمع درجات التلميذ على الإجابات الصحيحة فقط، بحيث تعطى لكل مفردة صحيحة نصف درجة أو درجة واحدة، والخطأ صفراً، كما استخدم نموذجاً لتصحح أوراق إجابات التلاميذ فى ضونئه.

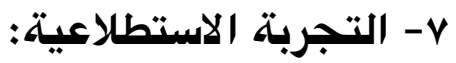

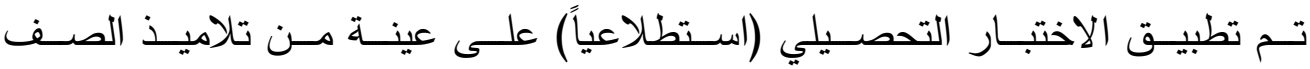

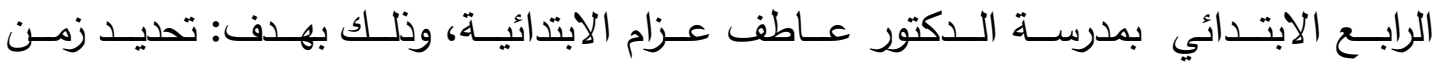

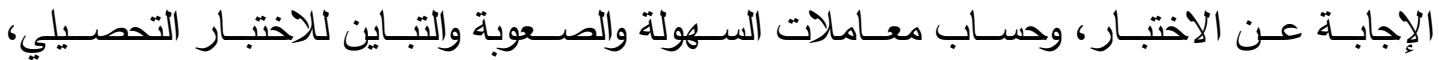

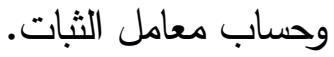

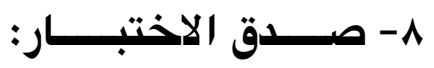

تم حساب صدق الاختبار بأكثر من طريقة منها:

1- 1- 1 - 1 صدق المحتوى:

ويعتمد صدق المحتوى على مدى التمثيل الصسادق للاختبار، أو المواقف التى يقيسها

بحيث يمثل الاختبار جميع الجوانب المقاسة، فقد قام الباحث بعرض الاختبار المعرفى، والوزن.

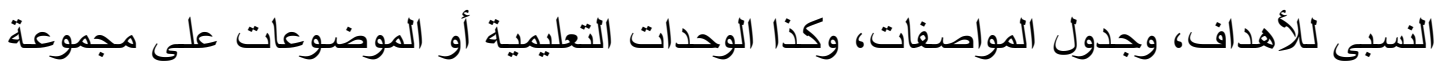
من المحكمين فى المناهج وطرق تدريس اللغة العربية والتربية الخاصـة وعلم النفس التعليمى لهى وطلب منهم إبداء الرأى حول:

1-مدى مناسبة أسئلة الاختبار لقياس المهارة التى وضع من أجلها.

$$
\text { r- مدى وضوح تعليمات الاختبار . }
$$

r- مدى كفاية الأسئلة لقياس الجوانب المعرفية المرتبطة بكل مهارة. ع - مدى مناسبة البدائل المشتقة لكل سؤال من الأسئلة. 0- سلامة الصياغة اللغويـة والعلمية لأسئلة الاختبار والجدول التالى يوضـح نسب اتفاق المحكمين على عناصر التحكيم السابقة. 


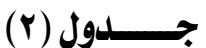

نسب اتفاق المحكميز على عناصر التحكيم المرتبطة بصدق الاختبار المعرفى

\begin{tabular}{|c|c|c|}
\hline نسبة الاتفاق & 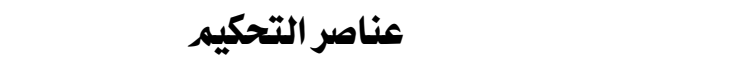 & مـ \\
\hline$\%$ & مدى مناسبة أسئلة الاختبار لقياس الكهارة التى وضع من أجلها & 1 \\
\hline$\%$. & مدى وضوح تعليمات الاختبار & r \\
\hline$\%$ \% & مدى كفاية الأسئلة لقياس الجوانب المعرفية المرتبطة بكل مهارة & $r$ \\
\hline$\%$. & ملدى مناسبة البدائل المشتقة لكل سؤال من الأسئلة & $\xi$ \\
\hline$\%$ & سلامة الصياغة اللفوية والعلمية لأسئلة الاختبار & 0 \\
\hline
\end{tabular}

كما طلب من المحكمين أن يضيفوا، أو يحذقوا، أو يعدلوا أية عناصر يرون أهميتها في بنـاء صدق الاختبار ، فأثـاروا بأن الاختبار طويل مما يجعل التلميذ يمل من الإجابة على مفرداته، وقد راعى الباحث ذلك فى الصورة النهائية للاختبار . 9- حساب المعاملات العلميتة لاختبار التحصيل في مههارتي التعرف على الكلمـتة

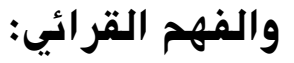

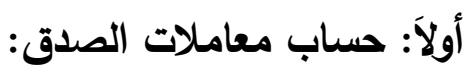

تم حساب معاملات الصدق لاختبار التحصيل في مهارتي التعرف على الكلمة والفهم القرائي بطريقة الصدق التمييزى: • حساب معامل الثبات لاختبار التحصيل في مهارتي التعرف على الكلمة والفهم القرائي قيد البحث: تم حساب معاملات الثبات لاختبار التحصيل في مهارتي التعرف على الكلمة والفهم القرائي قيد البحث بطريقتى مختلفتين هما : أ) طريقة تحليل التباين ( ألفا كرونباخ ) • ب) طريقة التجزئة النصفية ( سبيرمان براون ، جتمان ) • كما يتضح فى جدول (r) - (r) 


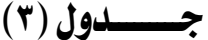

حساب معامل الثبات لاختبار التحصيل في مهارتي التعرف على الكلمة والفهر القرائي بطريقتى

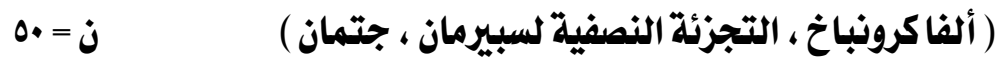

\begin{tabular}{|c|c|c|c|c|c|c|c|}
\hline \multicolumn{2}{|c|}{ التجزئة النصفية } & \multirow{2}{*}{ كرونباخ ألثا } & \multirow{2}{*}{ الاختبار } & \multicolumn{2}{|c|}{ التجزئة النصفية } & \multirow{2}{*}{ كرونباخ ألثا } & \multirow{2}{*}{ الأسئلة } \\
\hline جتمان & سبيرمان -براون & & & جتمان & سبيرمان -براون & & \\
\hline$\cdot, r \leqslant V$ & $\cdot, v \leqslant q$ & $\cdot, \Lambda \cdot r$ & 11 & •, Y৭\& & •, rvo & - AIr & 1 \\
\hline$\cdot, r \cdot r$ & $\cdot, r=0$ & $\cdot, \Lambda \cdot 0$ & ir & •, rrq & •, & •,AIr & $r$ \\
\hline$\cdot$, YrA & $\bullet, 7 \wedge$. & $\cdot, \Lambda \cdot \wedge$ & ir & •, rry & •, \{r| & $\cdot, \Lambda \mid \varepsilon$ & $r$ \\
\hline$\cdot$, rrI & - ,rrA & $\cdot, \Lambda \cdot \varepsilon$ & $1 \varepsilon$ & •, rrq & $\cdot, \wedge \wedge \neg$ & •, var & $\varepsilon$ \\
\hline$\cdot, Y \eta$ & •, OV\& & •, Аाళ & 10 & •, YrI & $\cdot, \vee 7 \wedge$ & $\cdot, \Lambda \cdot 1$ & 0 \\
\hline •, rAr & •, కYร & $\cdot, \Lambda \cdot \wedge$ & 17 & •, MIV & •, YAr & $\cdot, \Lambda \cdot V$ & 7 \\
\hline$\cdot$, rol & $\cdot, v \cdot \eta$ & $\cdot, \Lambda \cdot \vee$ & iv & $\cdot$, rrA & $\cdot, 77 r$ & $\cdot, \wedge I 1$ & $\checkmark$ \\
\hline •, rVs & - , vry & $\cdot, 1 \cdot 0$ & 11 & $\cdot, r \cdot \Lambda$ & $\bullet, \wedge 0$ & •, $\vee$ 91 & $\wedge$ \\
\hline$\cdot$, YrA & $\cdot, r 70$ & $\cdot, 110$ & 19 & $\cdot, \mathrm{YAT}$ & $\cdot, Y 17$ & $\cdot, 1 \cdot 0$ & 9 \\
\hline- & - & - & - & $\cdot, r \leqslant 0$ & •, vry & $\cdot, \Lambda \cdot r$ & 1. \\
\hline
\end{tabular}

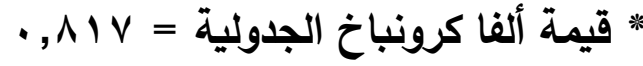

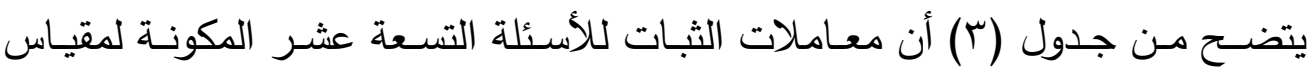
تثخيص صعوبات تعلم القراءة قد حقتت قيم مرتفعة فى جميع اسئلة الاختبار حيث تراوحت

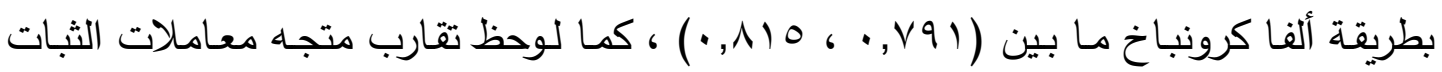

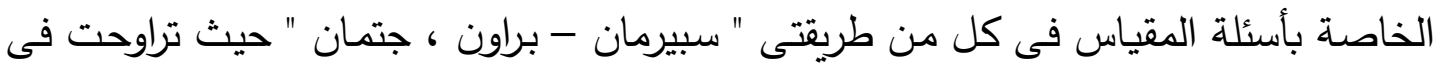

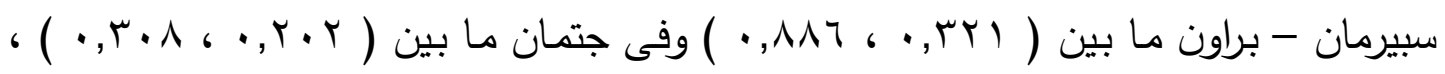

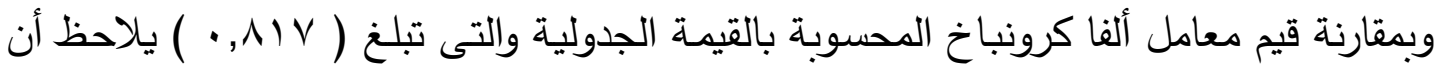

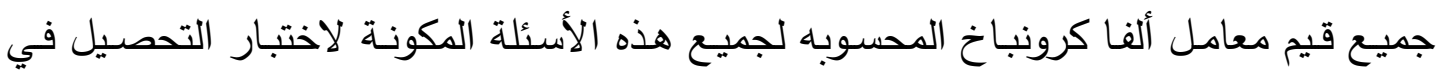

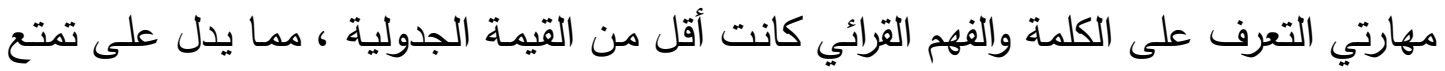
هذا الاختبار بدرجة عالية من الثبات .

\section{• ا- تحديد زمن الإجابة عن الاختبار:}

من خـلال التجربـة الاستطلاعية التى أجراهـا الباحث، قام بتحديد زمن الإجابة على لـى الاختبار، وذلك من خلال الوقت الذى استغرقه أسرع وأبطأ تلميذ باستخدام المعادلة التالية: 


$$
\text { أسرع تلميذ + أبطأ تلميذ }
$$

وبذلك يكون زمن الاجابة المناسبة للاختبار هو (ع ؟) دقيقة .

rا- الاختبار فى صورته النهائية

بعد الانتهاء من خطوات إعداد الاختبار ، والوثوق بدى صورثه صدقه وثباته، أصبح الاختبار

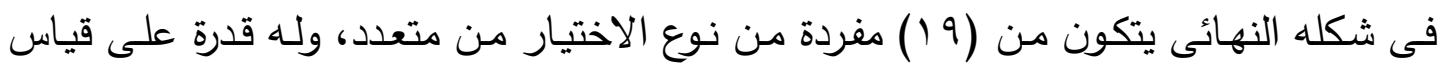

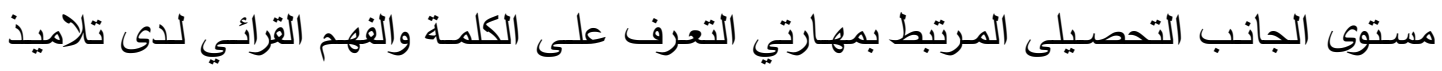

$$
\text { الصف الرابع الابتدائى. }
$$

\section{إعداد برنـامج الكمبيوتر:}

تتطلب عملية إعداد برامج الكمبيوتر جهداً كبيراً، حيث يعتمد على فريق عمل مكون من متخصصين فى إعداد المادة التعلمية والكمبيوتر • وتمر عملية إنتاج برامج الكمبيوتر بعدة مراحل:

$$
\text { 1- مرحلتة التخطيط: }
$$

\section{r- - تحديد الموضوع:}

قام الباحث بتحديد محتوى البرنامج الكمبيوترى من خلال كتاب اللغة العربية، المقرر على تلاميذ الصف الرابع الابتدائى ( اللغة في حياتي)، وبعض الكتب الخارجية المرتبطة به. r- مرحلة التصميم التربوى للبرنامج: تصن تمر عملية التصميم التربوى للبرنامج بعدة خطوات أساسية، تفيد في تصميم نموذج

$$
\begin{aligned}
& \text { تبنى عليه برامج الكمبيوتر، والخطوات هي : } \\
& \text { أ) تحديد الأهداف التدريسية: }
\end{aligned}
$$

يرتبط المحتوى بتحديد الأهداف التدريسية التى يسعى البرنامج لتحقيقها؛ حيث تساعد

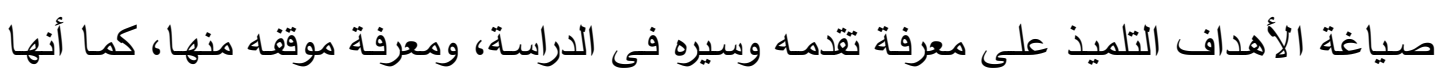
تساعد فى عملية التقويم.

وقد حددت أهداف برنامج الكمبيوتر فى شكل أهداف تدريسية عامة وبخاصـة مهارات التعرف على الكلمة والفهم القرائي، وأهداف سلوكية محددة يمكن قياسها وملاحظتها، وقد قام 
الباحث بتحليل مهارات التعرف على الكلمة والفهم القرائي إلى عناصرها الفرعية والجزئية، بحيث يمكن تحويلها إلى أهداف سلوكية يمكن قياسها. ب) تحديد استراتيجية التدريس: اختلفت استراتيجيات التدريس المستخدمة فى البرنامج وفقا لنمط تقديمه للتّلاميذ، ففى

حالة الطالب مع الكمبيوتر يتعلم التلميذ بمفردة من خلال جهاز الكمبيوتر فى ضوء استخدام

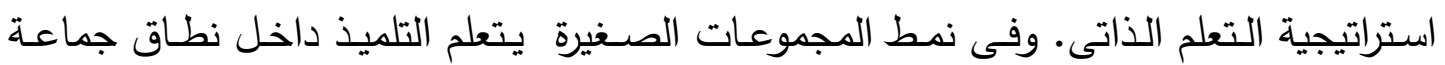
صغيرة وفق استراتيجية البحث الجماعى، حيث يتعاون جميع التلاميذ فى تحقيق الوصول

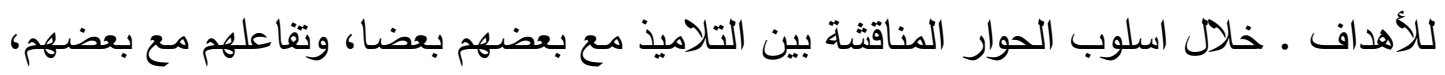

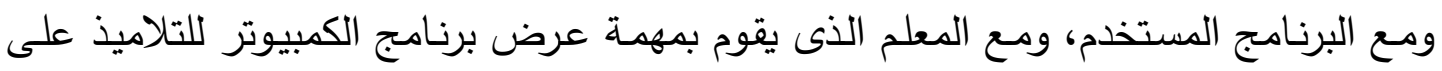

$$
\begin{aligned}
& \text { شاشة العرض الخارجية.(L.C.D.) } \\
& \text { ج) تحليـل المحتــوى: }
\end{aligned}
$$

يعد تحليل المحتوى من أهم الخطوات الضرورية اللازمة لإعداد برنامج الكمبيوتر على لمى

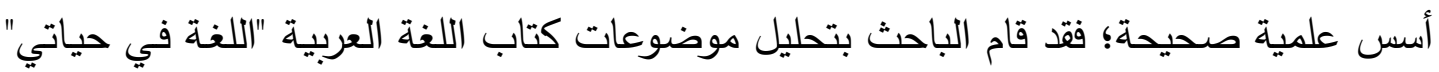

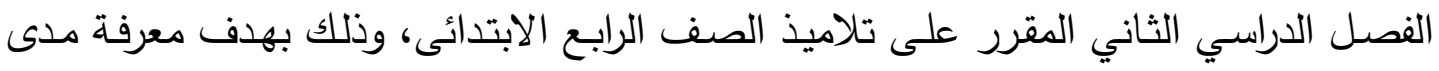

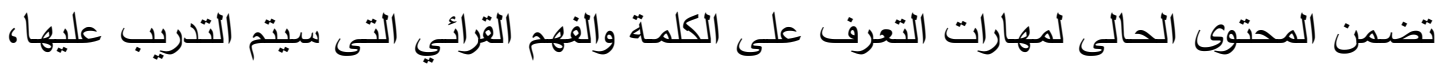

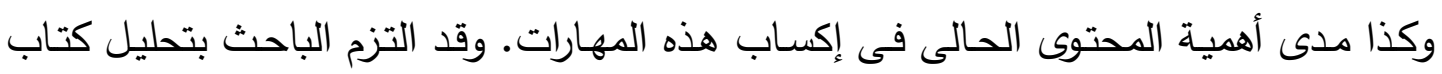

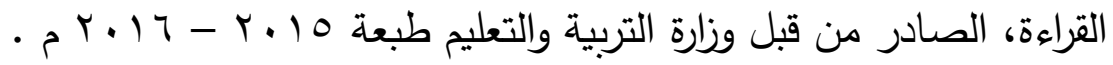
د) توفير مصادر المادة التعليمية : تم تجميع الكتب والمراجع المتصلة بالمحتوى التعليمى في الفصل الدراسي الثاني وهى:

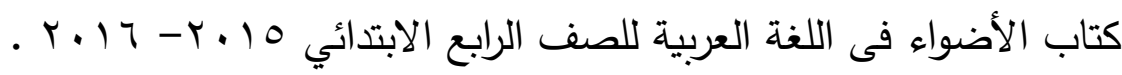

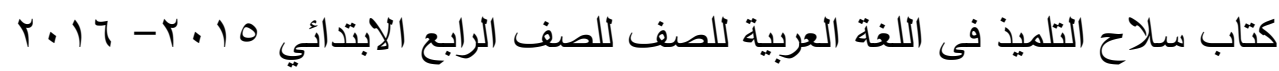
ه الرجوع إلى قوائم الدفردات المناسبة لتلاميذ المرحلة الابتدائية.

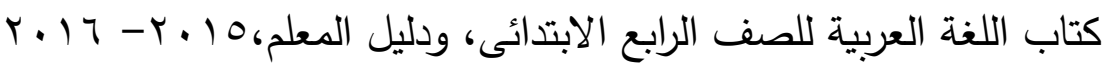
هـ) التقــــــــــ ويقصد بالتقويم هنا عملية ضبط البرنامج، وتتضمن هذه المرحلة خطوتين هما: تثغيل

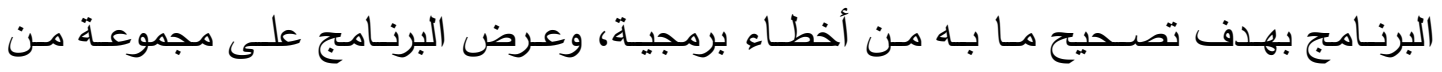


المحكمين المتخصصين فى مجال تكنولوجيا التعليم، وسوف يتحدث الباحث عن هذه الخطوة بالتفصيل أثناء مرحلة التصميم الفنى للبرنامج. وقد روعى عن تصميم الموضوعات التعليمية اشتمالها على المكونات الرئيسة وهى: مكونات نظام الاخول الى البرنامج : وتثمل:

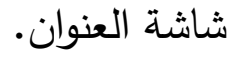

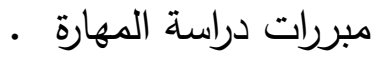

الأهداف التعليمية للمهارة .

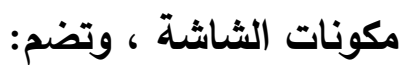

المحتوى المراد تعلمه، والأنشطة التعليمية التى يجب أن يقوم بها المتعلم ، والوسائل التعليمية المرتبطة، والتمارين، والاختبارات القصيرة للتقويم الذاتى، والتغذية الراجعة المصححة

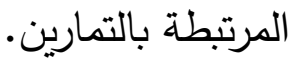
وفى ضوء ما سبق أمكن بناء صورة البرنامج الورقية المطبوعة، وقام الباحث بالتأكد من صلاحتيها، من خلال توزيعها على مجموعة من المتخصصين • لماه مرحلة التصميم الفنى للبرنامج: وتتمثل أنشطة هذه المرحلة فيما يلى: أ) ) تحديد أنماط التفاعل مع البرنامج: ويراد بها الوسائل التى ينتجها البرنامج للمتعلم للتعبير عن استجاباته، وقد استخدم الباحث "النقر" بالفأرة Click كنمط للتفاعل داخل البرنامج؛ لأنه أبسط أنماط التفاعل ولأنه يناسب تلاميذ الصف الرابع الابتدائى. ب) تحويل المحتوى إلى سيناريو

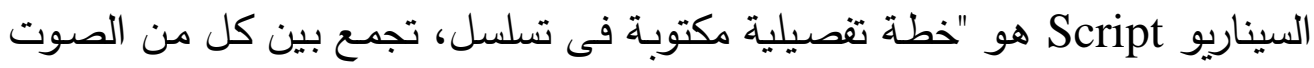

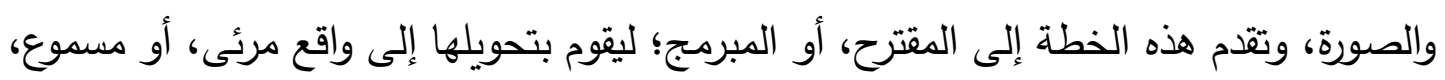

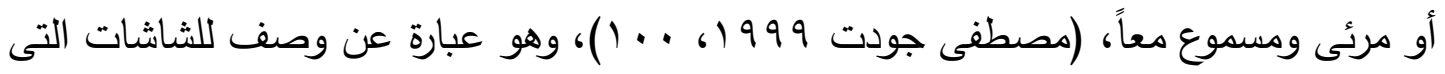
سيتم تصميمها بمـا يتضمنه مـن نصوص وصسور ثابتة ومتحركـة وصسوت وموسيقى، ويعد

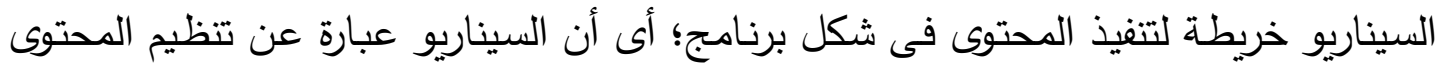
بطريقة تربطه بالوسائل المستخدمة فى البرنامج، بحيث يسهل تتفيذ هذا المحتوى فى شكل بل بن 
برنامج، ويحدد هذا السيناريو شكل الثاشة والتصميم العام لها وموقع وزمن عرض كل وسيلة فى البرنامج والتنسيق بين تلك الوسائل. وقد قام الباحث بعمل سيناريو البرنامج الكمبيوتري ـ

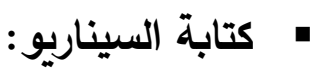

وتم فى هذه المرحلة كتابة السيناريو لجلسات البرنامج التى سيتم تنفيذها بعد ذلك، كما قام الباحث بعد كتابة السيناريو بتجهيز كل متطلباته (عناصر عرض برنامج الكببيوتر) إعدادًا لمرحلة الإنتاج، وقد تم تتبيت كل عنصر من عناصر محتوى الثريحة فى مكانه لعدم تشتيت الطالب أثناء التعامل مع برنامج الكمبيوتر وقد أمكن تمثيل هذا السيناريو فى الثكل التالى: شكل(r) يوضح التمثيل النهائي لنهط شاشة العرض تصني

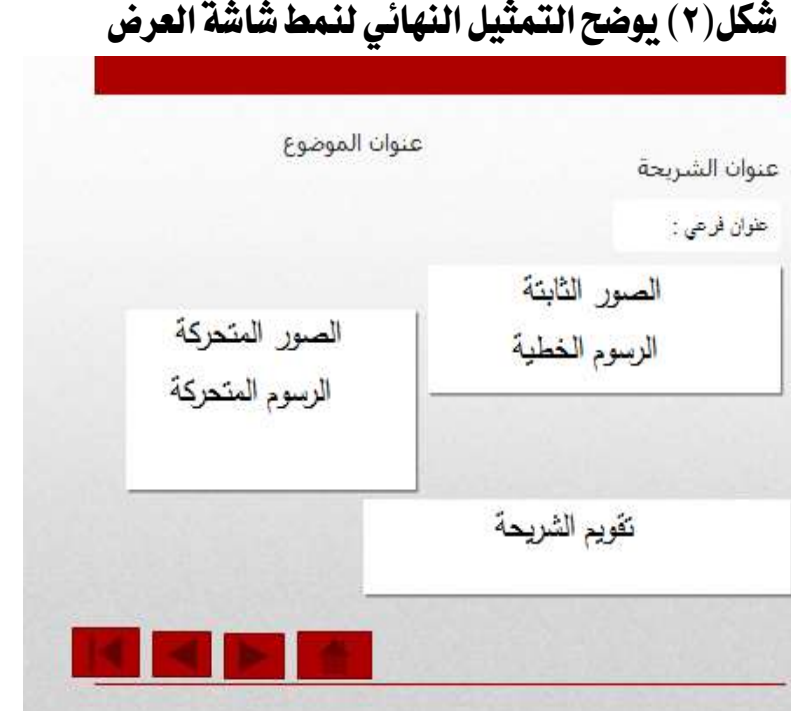

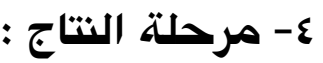

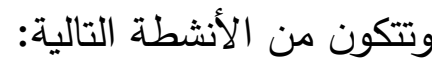

أ) أ تحديد الوسائل ونتاجها:

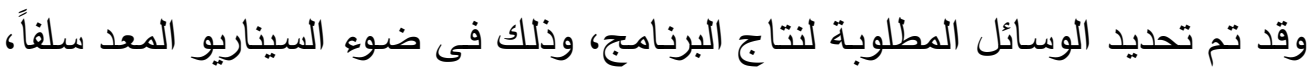

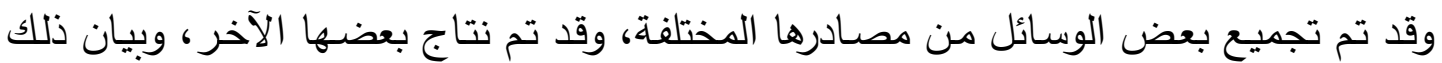

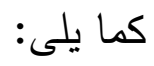

فيما يتصل بالصور الثابتة Still Pictures تم الحصول على بعض الصور الثابتة المعبرة عن المحتوى المقدم من خـلال كتاب

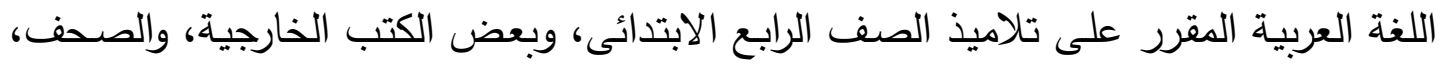


والمجلات التعليمية والثقافية والمواقع التعليمية على شبكة الانترنت وبعض الموسوعات التى تم تخزينها على جهاز الكمبيوتر ·

وقد تم نتاج بعض الصور الثابتة من خلال (كاميرا فوتوغرافيا) لبعض الصور التى تخدم المحتوى التعليمى وقد تم توظيف هذه الصور أثناء عرض البرنامج لتوضيح الأثكال الحقيقة، وتمثيل الخبرات الواقعية. فيما يتصل بالصور المتحركة Motion Pictures ولهـا كثير مـن الفوائد فـى عـروض البرامج الكمبيوتريـة فـى نقل الصـوت والصـورة والحركة، بالإضـافة إلى أنها تساعد المتعلم على التركيز، وعدم الملل من مواصلة العرض،

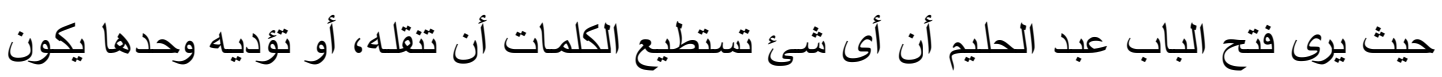

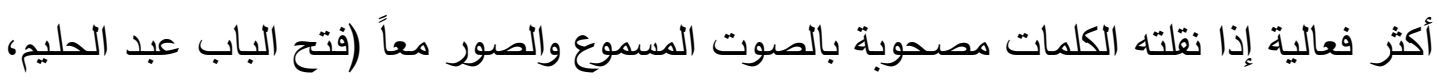
1990، T/ (Y)، وقد تم الحصول على بعض الصور المتحركة من خلال عدة مصادر هى:

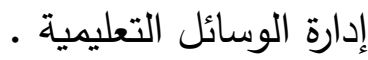

• مكتبات بعض الكليات والمراكز العلمية و مركز التطوير التكنولوجي التابع لوزارة التربية والتعليم ومعمل تكنولوجيا التعليم بالإدارة التعليمية .

فيما يتصل باللغة المنطوقة Spoken word: تم تسجيل النصـوص المسموعة ولغـة البرنـامج المنطوقـة والتىى تحتـوى على شـرح

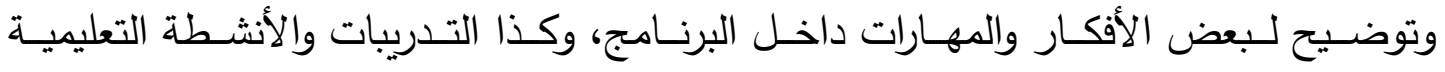
والإضافية.

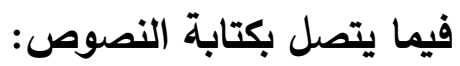

تم تجميع النصوص من كتاب التلميذ المدرسى فى اللغة العربية (اللغة في حياتي)، وتمثلت فى شكل نصوص وموضوعات قرائية ، وبعض الجمل والفقرات التى تستخدم لتوضيح

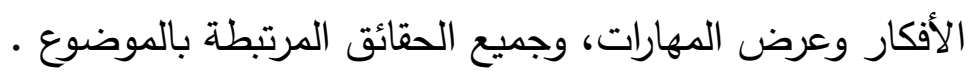
فيما يتصل بالموسيقى والمؤثرات الصوتية : تم توظيف بعض الخلفيات الموسيقية المناسبة لعرض النصوص المسموعة والمقروءة، وكذا خلال فترة التدريب، وأثناء عرض الأنثطة التعليمية. 
وبعد تجهيز الأدوات والأجهزة السـابقة وفى ضـوء كتابـة السيناريو ، وتوفير الوسـائل

التعليمية ، تمت عملية الإنتاج الفعلى للبرنامج، واستمرت عملية الإنتاج مـا يزيد عن ثمانية

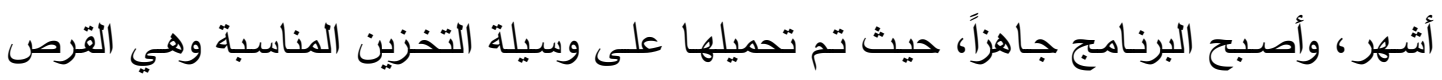
القابل للازالة (الفلاشة).

\section{ج) وصف البرنامج الكمبيوترى:}

يشتمل البرنامج على عدد من الموضوعات كل موضوع يتصل بتتمية مهارة أو أكثر

من مهارات التعرف على الكلمة والفهم القرائي.

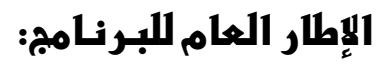

راعى الباحث عدة نقاط عند إعداد شاشـات البرنامج مثل: خلو البرنامج من العيوب

الفنية والعلمية، والاستخدام الملائم للألوان، والرسوم، وخلق عنصر التشويق وتوفير بيئة تعليمية جيدة، ويمكن تصنيف شاشات البرنامج على النحو التالى:

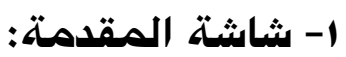

وهى المسئولة عن واجهة البرنامج الكمبيوترى وذلك من خلال شاشـة واحدة يتم من

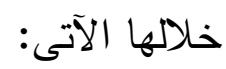

أ) شاشـة افتتاحية يظهر من خلالها نص قرآنـى مكتوب "|قرأ باسم ربك الذى خلق، خلق

الإنسان من علق، اقرأ وربك الأكرم، الذى علم بالقلم، علم الإنسان ما لم يعلم" ـ (ش ( ) ب) شاشات التعريف بالبرمجية ووضحت هذه الثاشات ما يلى:

جامعة قناة السويس

( ش)

كلية التربية

(乡)

قسم التربية الخاصة

فمالية التعليم بمساعدة الكمبيوتر في تنمية بعض مهارات القراءة لدى تلاميذ الصف الرابع (ش ه) الابتدائي ذوي صعوبات التعله 
ويظهر فى هذه الثاشات توظيف الفلاشات، وتأثيرات الحركة، وألوان الكتابة، وألوان

الخفيات، فى شكل يثد انتباه التلاميذ، ومصحوبا بالخلفية الموسيقية .

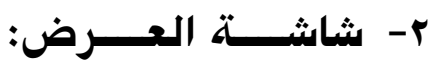

ويتم من خلالها عرض عنوان الموضوع، وابتداء من هذه الثاشـة تظهر المشـاركة

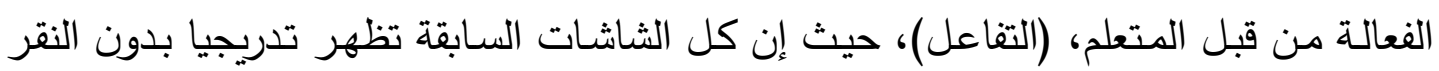

بالفأرة (تتحرك بثكل آلى).

وقد تم تحديد مجموعة من مفاتيح التحكم أسفل كل شاشة من الثاشات السابقة وهى:

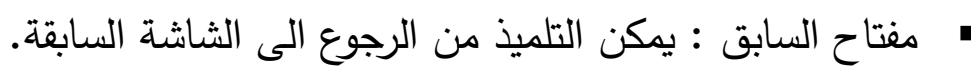

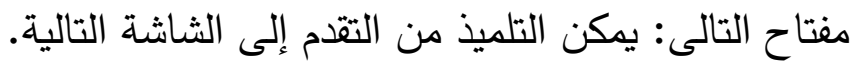

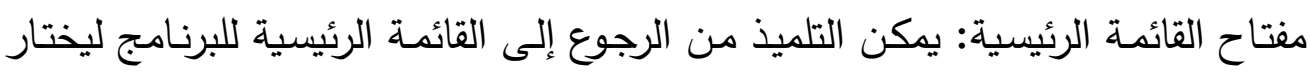
من بينها ما يرغب في تعلمه.

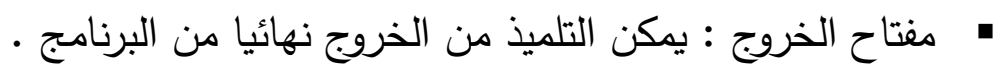

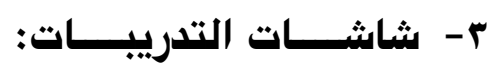

وتظهر هذه الثاشات فى نهاية تعلم بعض أجزاء من المحتوى التعليمى، وفى حالتى التى

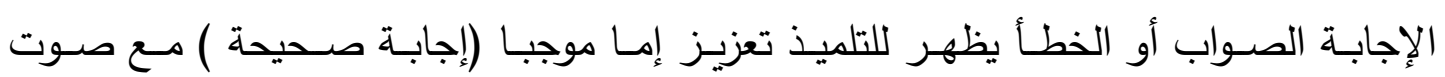

التصفيق، وإما سالباً (إجابة خاطئة).

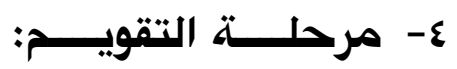

بعد الانتهاء من إعداد البرنامج ثم عرضه على مجموعة من المحكمين فى تخصصات

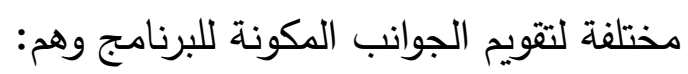
هتخصصون فى طرق تعليم اللغة العربية. هتخصصون فى التربية الخاصة وعلم النفس. متخصصون فى مجال تكنولوجيا التعلم.

وذلك للحكم على سلامة البرنامج طبقا للمعايير والمحكات التالية:

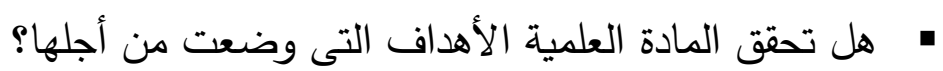

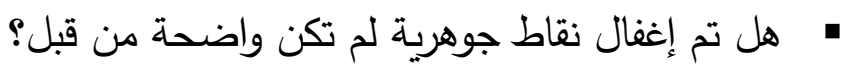

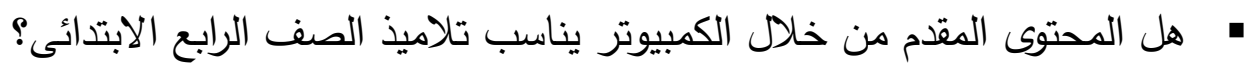

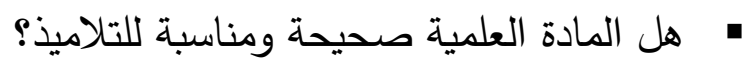
ما مدى تناسق الأهداف السلوكية مع المحتوى وأسئلة الاختبار؟ 
ما مدى جودة الصوت بالبرنامج؟ ما مدى جودة الصور الثابتة بالبرنامج؟ ما مدى مناسبة موقع النص على شاشة الكمبيوتر؟ ماتج

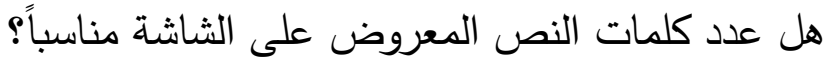
ما مدى تناسق الخلفيات مع الصور والنصوص التى تعرض عليها؟

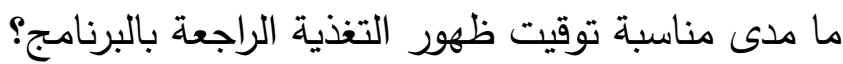

هل مدة عرض البرنامج مناسبة للتلاميذ؟ • هل يمكن أن يحقق البرنامج التقاعل بين التلاميذ والمادة التعليمية؟ هل يوجد اتساق بين أسلوب العرض، واستراتيجية التظظيم المحددة بكل البرامج ؟ * وقد أبدى المحكمون اقتراحات وملاحظات على البرنامج منها: ضرورة تناسق الخلفية مع ما يكتب عليها. ضرورة توحيد الخلفيات فى كل الثاشات. إجراء بعض التعديلات فى الصـوت بالقدر الذى يظهر للتلميذ الفروق الجوهريـة بين مخارج الحروف.

مراعاة الاتساق بين النصوص، والصور الثابتة والمتحركة الموجودة على الثاشة. تكوين بعض الحروف والكلمات المرتبطة بالمهارة التى يتم التدريب عليها بألوان واضحة.

0- التجربة الاستطلاعيـــة:

بعد قيام الباحث بإجراء التعديلات المطلوبـة، قام بإجراء التجربـة الاستطلاعية بهدف التأكد من وضوح المادة العلمية المتضمنة فى البرنامج، ومدى مناسبة محتوى البرنامج للتلاميذ، وكذا وضوح الأشكال، والصور ، وبنط الكتابة، ولحساب الفاعلية الداخلية للبرنامج ومدى التفاعل بين التلاميذ والكمبيوتر، ومدى مناسبة اللوحة المسـارية، وأسلوب التغذيـة الراجعة الذى يقدم داخل البرنامج، ومدى توظيف معانى المفردات فى الغرض الذى أنثأت من أجله. وقد أظهر التلاميذ تقبلاً وحماسـاً كبيرين لأسلوب عرض البرنـامج فى تقديم المـادة التعليمية بما تتضمنه من مؤثرات بصرية وأصوات ، وتغذية راجعة، والسماح للتلميذ بأن يسير فى البرنامج وفق سرعته الخاصة، وتقبل التلميذ للبرنامج، وزيادة حجم التفاعل معه، وقد أظهر التلاميذ نتائج إيجابية. البرنامج. 


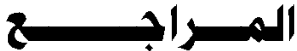

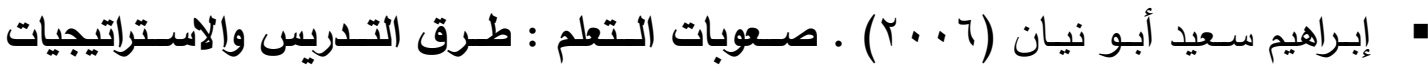

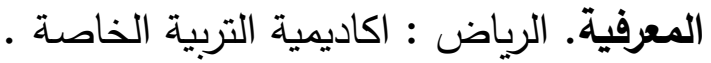

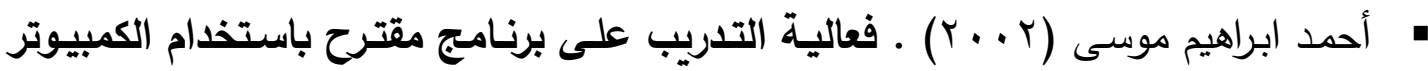

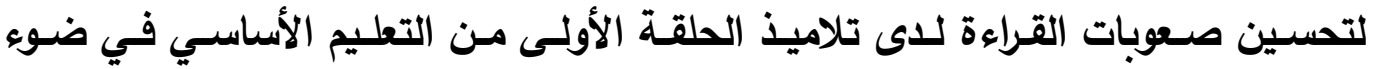
النموذج الكلي لوظائف المخ . ( رسالة ماجستير غير منشورة). جامعة طنطا.

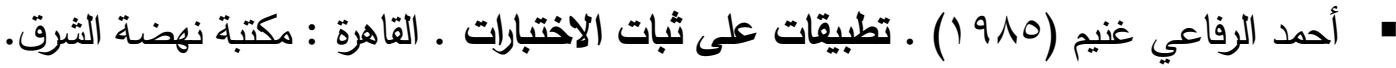

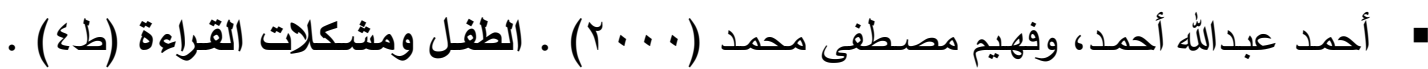

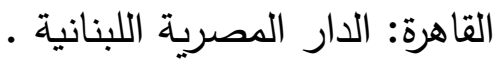

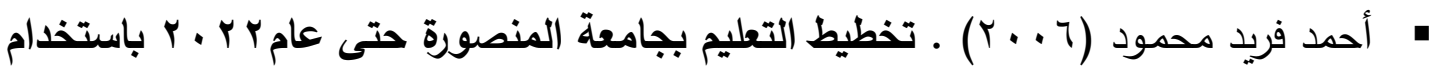
أسلوب التخطيط الاستراتيجي. (رسالة دكتوراه غير منشورة). جامعة المنصورة. جمهورية

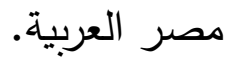

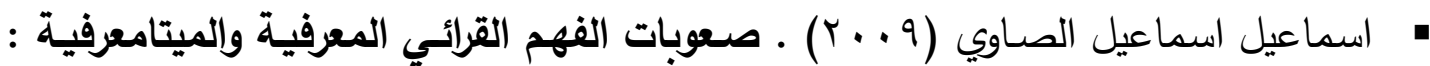

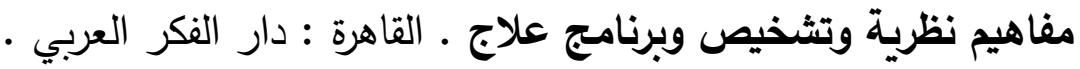

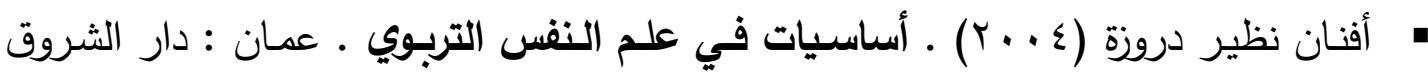

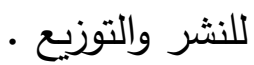

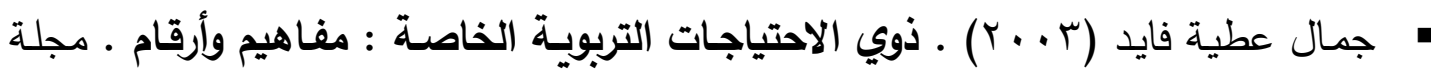

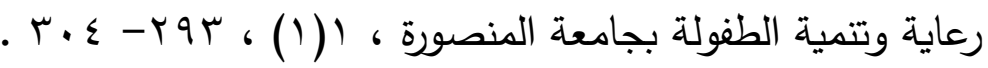

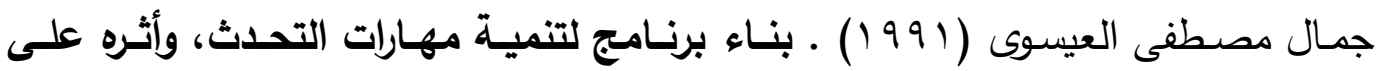
الاستماع الهادف للدى تلاميذ الصفين الرابـع والخـامس مـن التعليم الأساسـى. (رسالة دكتوراه غير منشورة ) .جامعة طنطا ـ جمهورية مصر العربية.

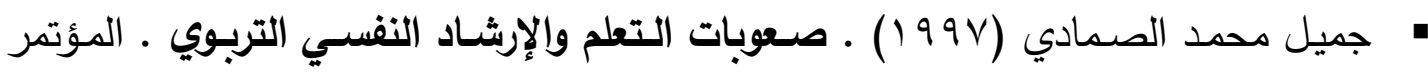
الدولي الرابع لمركز الإرشاد النفسي والمجال التربوي بجامعة عين شمس ، ، ، 79 ـ 1. $1 Y / \varepsilon-r_{6} 1 \cdot \Lambda 1$

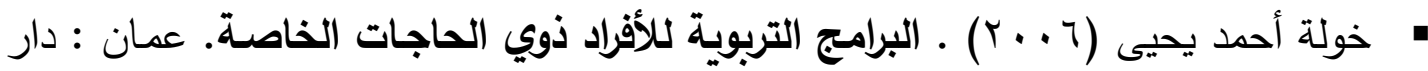

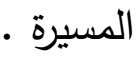


دانيال هالاهان، وجون لويد، وجيمس كوفمان، ومارجريت ويس، وإليزابيث مارتيز ( . . ץ).

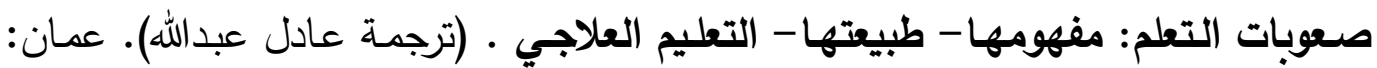

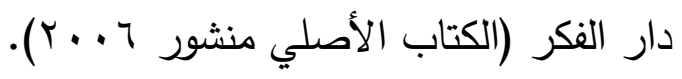

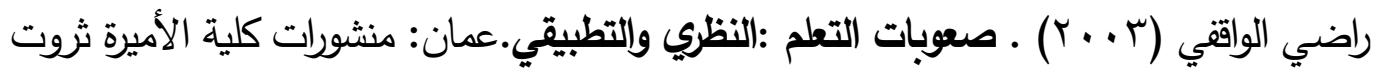

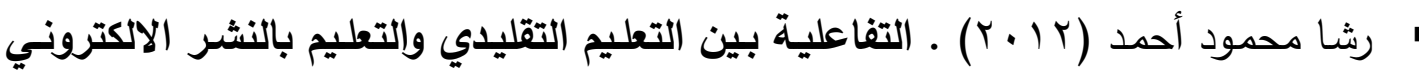
لقياس كفـاءة التعليم المـدوج • (رسالة دكتوراه غير منشورة) .جامعة حلوان. جمهوريـة

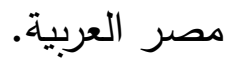

رمضان رفعت محمد سليمان( ؟99 1) .استخدام الكمبيوتر فى تلريس الرياضيات للتلاميذ الصم وأثر ذلك على تحصيلهم واتجاهاتهم نحو الرياضيات . ( رسالة دكتوراه غير منشورة). جامعة المنوفية. جمهورية مصر العربية.

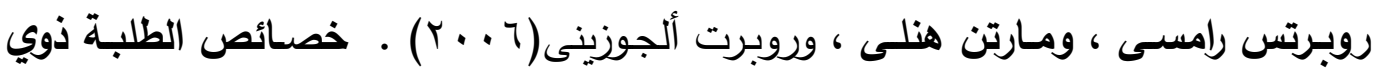

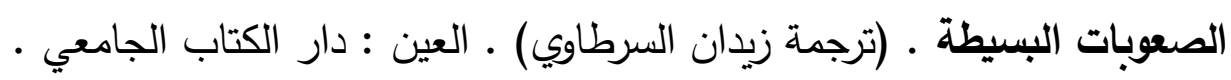

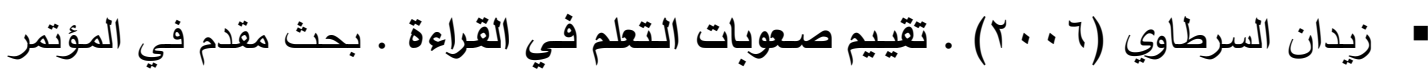

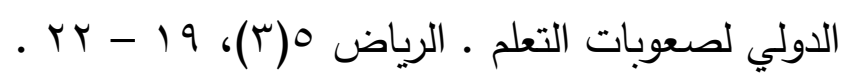

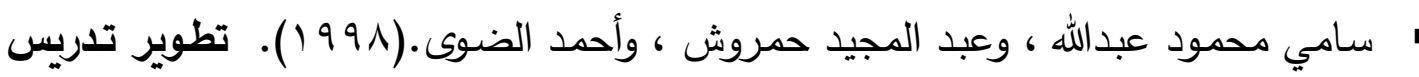

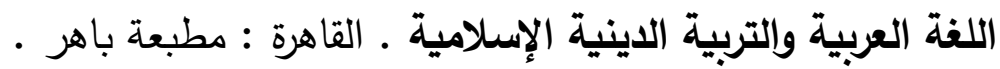

- Aleven,V.,\&Grassev,A.(2013). Intraoduction tospeciol issue on advanced learning technologies. Jounal of Educational psychology,3(4), 929- 931

- Armstrong, T.(2000).Multiple Intelligences in the Classroom. on-line: http://www.ascd.org.

- Beltzman, J.(1994). A Case Study Describing the Application of Howard Gardner's Theory of Multiple Intelligences as Applied to the Teaching of Learning Disabled.Dissertation Abstracts International ,56(66),21-23.

- Bentum, K.,\&Aaron,P.(2003). Does reading instruenction in learning disability resource rooms really work?: Alongitudinal study. Journal of reading psychology,24(3),125-127.

- Chall, S.(1991). American reading instruction science, art and ideology in W. Ellis (Ed). All language and the creation of Literacy Baltimore. MD: orton dyslexia society,25-27. 